\title{
Comparative photophysical behaviour of naphthalene-linked crown ethers and aza crown ethers of varying cavity dimensions
}

\author{
SUBHODIP SAMANTA, PINKI SAHA SARDAR, SHYAM SUNDAR MAITY, \\ ANIRBAN PAL, MAITRAYEE BASU ROY and SANJIB GHOSH* \\ Department of Chemistry, Presidency College, Kolkata 700073 \\ e-mail: sanjibg@cal2.vsnl.net.in
}

\begin{abstract}
A comparative time-resolved emission studies of several naphtho-crown ethers I-V, where metal ions can be complexed in a predetermined orientation with respect to the naphthalene (Naph) $\pi$ plane and naphthalene-linked aza crown ethers (L1 and L2) have been presented. In both the systems, crown ethers and aza crown ethers, naphthalene fluorescence gets quenched. In the systems I to $\mathbf{V}$, the quenching is mainly due to efficient spin-orbit coupling (SOC) leading to greater population of the lowest triplet state of naphthalene. This SOC depends on the orientation of the crown ring with respect to the Naph- $\pi$-plane. However, in the systems L1 and L2, the quenching is due to photoinduced electron transfer (PET) from nitrogen lone pair of the aza crown ring to naphthalene moiety and consequent exciplex formation. The results have been interpreted using the time-resolved emission studies of all the compounds in various solvents, their alkali metal ion complexes, and protonated ligands.
\end{abstract}

Keywords. Photoinduced electron transfer; exciplex; fluorescence; naphthalene-aza-crown ethers; napthocrown ethers; fluorescence lifetimes.

\section{Introduction}

Photophysical behaviour of systems with the configuration of 'fluorophore-spacer-receptor' are markedly affected by (i) the nature of fluorophore, (ii) the length and nature of the spacer, (iii) the cavity dimension of the receptor moiety, and (iv) the presence of cations in the receptor cavity. These systems are important for their potential uses as efficient molecular sensors, switches, molecular logic processes and to understand the mechanism of photoinduced electron transfer (PET) ${ }^{1-4}$ Systems having anthracene, pyrene, naphthalene, or coumarin as the fluorophore moiety attached to different crown ethers, aza crown ethers and cryptands by spacers of varying chain lengths and varying cavity dimensions of the receptor moiety have been reported from our laboratory. ${ }^{5-12}$ These systems are also of great interest in view of their importance as model systems to study ion transport phenomena, ${ }^{13}$ to understand electric field-induced conformational changes in proteins ${ }^{14}$ and to find photoinduced energy transfer pathways in proteins. ${ }^{15}$

We report here the steady-state and time-resolved fluorescence of 2,3-naphtho-17-crown-5 (I), 2,3naphtho-20-crown-6 (II), 1,8-naphtho-21-crown-6

\footnotetext{
*For correspondence
}

(III), 1,5-naphtho-22-crown-6 (IV), 1,4-naphtho-22crown-6 (V) (figure 1) and the alkali metal ion complexes of $\mathbf{I}$ to $\mathbf{V}$ in EtOH at room temperature $(298 \mathrm{~K})$. We use $\mathrm{Na}^{+}$ion for crown-5 ethers and $\mathrm{K}^{+}$ ion for crown- 6 ethers. In the complexes the metal ion bound to the crown cavity is located along the $Z$ axis (in-plane long axis of naphthalene (Naph) $\pi$ plane in I and II, the Naph plane and the $\pi$-plane lie in the $Y Z$ plane), $Y$-axis (in-plane short axis of Naph$\pi$-plane in III), and $X$-axis (perpendicular to the Naph- $\pi$-plane in IV) ${ }^{9,10}$ In the complex $\mathbf{V}$, the metal ion is situated on the axis (passing through the centre of one benzene ring) perpendicular to the Naph- $\pi$ plane.

The photophysical behaviour of these systems at room temperature has been compared with those of two derivatives of $\mathrm{N}-(\beta$-methyl naphthalene) mono aza-crown ether systems where a naphthalene unit is attached to aza-crown ether rings of varying cavity dimension through the same spacer (L1 and L2, figure 1). In these compounds, due to the presence of nitrogen atom in the aza-crown rings, the phenomena of photoinduced electron transfer (PET) at room temperature is expected to be observed. Steady-state and time-resolved emission behaviour has been studied in the free ligands in different solvents, in the protonated ligands and in the complexes of the ligands 

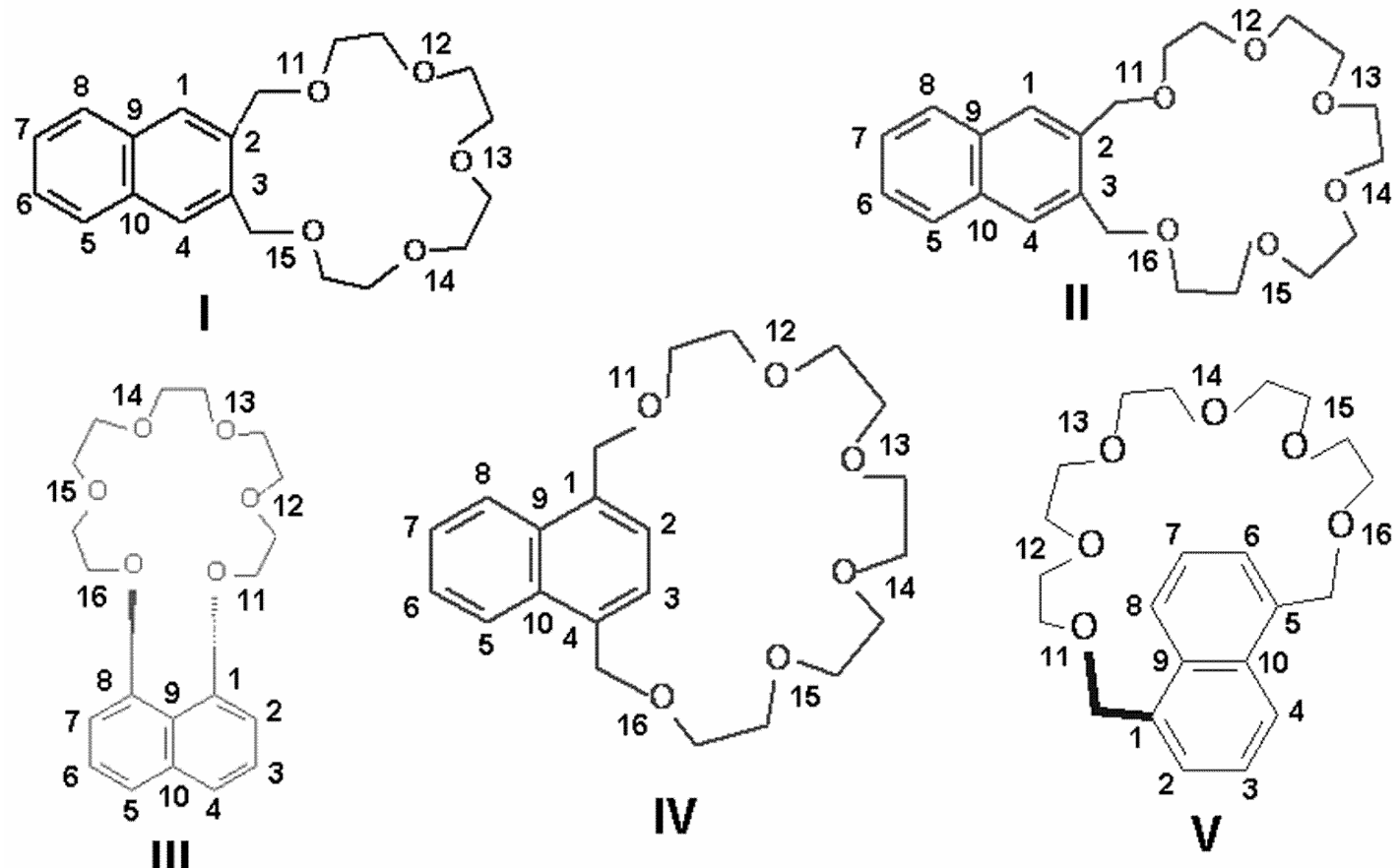<smiles>c1ccc2cc(CN3CCOCCOCCOCCOCC3)ccc2c1</smiles>

L1<smiles>c1ccc2cc(CN3CCOCCOCCOCCOCC3)ccc2c1</smiles>

L2

Figure 1. Structural representation of: 2,3-naphtho-17-crown-5 (I); 2,3-naphtho-20-crown-6 (II); 1,8-naphtho-21-crown-6 (III); 1,5-naphtho-22-crown-6 (IV); 1,4-naphtho-22-crown-6 (V); $\mathrm{N}-(\beta$-methylnaphthalene) monoaza-15-crown-5 (L1), N-( $\beta$-methylnaphthalene) monoaza-18crown-6 (L2).

with $\mathrm{Li}^{+}$and $\mathrm{K}^{+}$ions. The difference in behaviour of the two systems can be attributed to subtle changes in the total architecture of the systems provided by the varying cavity dimension of the aza-crown ether unit.

\section{Experimental}

\subsection{Materials}

All chemicals were of reagent grade, which were used without further purification unless otherwise noted. THF, benzene, EtOH, and other solvents used were obtained from Merck (India). They were purified prior to use following standard procedures and then dried. The compounds 1-aza-15-crown-5 and 1-aza18 -crown- 6 and $\beta$-bromo methyl naphthalene were obtained from Aldrich (US).

\subsection{Preparation and purification of compounds}

2.2a Naphtho-crown ethers: The crown ether compounds 2,3-naphtho-17-crown-5 (I), 2,3-naphtho-20crown-6 (II), 1,8-naphtho-21-crown-6 (III), 1,5naphtho-22-crown-6 (IV), 1,4-naphtho-22-crown-6 (V) in extremely pure form were obtained as gifts from Prof L R Sousa, Department of Chemistry, Ball State University, Muncie, IN 47306, USA. ${ }^{16}$

$2.2 \mathrm{~b}$ Synthesis of $N-(\beta$-methyl naphthalene) monoaza-15-crown-5 (L1) and $N$-( $\beta$-methylnaphthalene) monoaza-18-crown-6 (L2): For the synthesis of L2, $1.1 \mathrm{mmol}$ of $\beta$-bromo methyl naphthalene $(0.25 \mathrm{~g})$ in $10 \mathrm{ml}$ benzene was added to a $1.1 \mathrm{mmol}$ solution of 1-aza-18-crown-6 (0.3 g) in $8 \mathrm{ml}$ benzene with stirring. To the solution was added potassium carbonate $(1.5 \mathrm{mmol})$ and potassium iodide $(20 \mathrm{mg})$ all at once. 
The mixture was refluxed for about $12 \mathrm{~h}$ and at the end of the period the reaction mixture was filtered. The solvent was removed under reduced pressure; the residual mass was shaken with $5 \mathrm{ml}$ water. The desired compound was extracted from the aqueous medium with chloroform $(4 \times 5 \mathrm{ml})$. The chloroform layer was dried over anhydrous sodium sulphate and then chloroform was evaporated to obtain brown oil. ${ }^{1} \mathrm{H}$ NMR $\left(\mathrm{CDCl}_{3}, 25^{\circ} \mathrm{C}\right): \delta \mathrm{ppm} \mathrm{8.28-7.49}(\mathrm{m}, 7 \mathrm{H})$, $4.90(s, 2 \mathrm{H}), 3.88-3.54(m, 20 \mathrm{H})$ and $2.54(s, 4 \mathrm{H})$.

The procedure for the synthesis of $\mathrm{L} 1$ is essentially the same as described above. ${ }^{1} \mathrm{H}$ NMR $\left(\mathrm{CDCl}_{3}\right.$, $\left.25^{\circ} \mathrm{C}\right): \delta \mathrm{ppm} \mathrm{8.14-7.48}(\mathrm{m}, 7 \mathrm{H}), 4.77(s, 2 \mathrm{H}), 4.03-$ $3.58(m, 20 \mathrm{H})$

The NMR data ensure the formation of the ligands and also the purity of the products (see $\$ 3.1$ ).

\subsection{Instrumentation}

The steady-state absorption and emission measurements were carried out using a Hitachi Model 3021 spectrophotometer and a Hitachi Model 4010 spectrofluorimeter equipped with a $150-\mathrm{W}$ xenon lamp) respectively, at $298 \mathrm{~K}$ using a stoppered cell of $1 \mathrm{~cm}$ path length. All emission measurements were performed after purging the solution with pure argon gas for $30 \mathrm{~min}$.

Fluorescence quantum yield was determined in each case by comparing the corrected spectrum of the samples with that of pure naphthalene in THF by taking the total area under the emission curve in each case. The quantum yield of pure naphthalene in THF was measured using quinine sulphate in $1 \mathrm{M}$ $\mathrm{H}_{2} \mathrm{SO}_{4}$ as in the literature. ${ }^{17}$ and the standard quantum yield value thus obtained was used for the calculation of quantum yields of the systems under various conditions.

Time-resolved emission studies were carried out in a Time Master Fluorimeter from Photon Technology International (PTI), USA. The system measures the fluorescence lifetime using PTI's patented strobe technique and gated detection. The software Felix 32 controls all acquisition modes and data analysis of the Time Master system. The sample was excited using a thyratron-gated nitrogen flash lamp FWHM $1.2 \mathrm{~ns}$ that is capable of measuring fluorescence time-resolved acquisition at a flash rate of $25 \mathrm{kHz}$. Lamp profiles were measured at the excitation wavelength using slits with a band pass of $3 \mathrm{~nm}$ using Ludox as the scatterer. The decay parameters were recovered using a nonlinear iterative fitting proce- dure based on the Marquardt algorithm. The quality of fit has been assessed over the entire decay, including the rising edge, and tested with a plot of weighted residuals and other statistical parameters, e.g. the reduced $\chi^{2}$ ratio.

\section{Results and discussions}

\subsection{Geometry of the naphtho-crown ethers II to $\mathbf{V}$}

Ground-state geometries of free naphtho-crown ethers (II-V) were fully optimized by DFT/B3LYP level of theory using $6-31+\mathrm{G}^{*}$ basis set ${ }^{18 a}$ to a local minima. The dihedral angle between the Naph- $\pi$ plane (YZ-plane, defined by the carbon atoms $\mathrm{C} 1$ to C10 (figure 1) in the Naph- $\pi$ ring) and the planes containing each oxygen atoms of the crown ether ring (defined by the carbon atoms in the centre of the Naph- $\pi$ plane, e.g. C9 and C10 (figure 1) and the respective oxygen atom) for II to $\mathbf{V}$ are given in table 1 . These dihedral angles describe the angle the respective oxygen atoms make with respect to the Naph- $\pi$ plane. ${ }^{18 \mathrm{~b}}$ The optimized geometry of II and III show that six oxygen atoms are situated more or less in plane to the Naph- $\pi$ plane and in the IV and $\mathbf{V}$ these are situated out of plane.

\subsection{Steady-state and time-resolved emission studies of naphtho crown ethers $\mathbf{I}$ to $\mathbf{V}$ and their $\mathrm{Na}^{+} / \mathrm{K}^{+}$ion complexes}

The fluorescence spectra of free $\mathbf{I}$ to $\mathbf{V}$, the $\mathrm{Na}^{+}$ion complex of $\mathbf{I}$, and $\mathrm{K}^{+}$ion complexes of $\mathbf{I I}$ to $\mathbf{V}$ are presented in figure 2. Although the fluorescence spectra of I, II, IV, and $\mathbf{V}$ and their metal ion complexes are structured, those of III and its metal ion complex are devoid of any structure. This is probably due to the difference in the flexibility of the crown ring with respect to the Naph plane which affects vibronic coupling. The intensity of fluorescence is enhanced for the metal ion complexes in each case. The position of maxima in the fluorescence and fluorescence quantum yield for the free naphthocrown ethers and their respective metal ion complexes are given in table 2 . The minimum enhancement of fluorescence quantum yield is observed for IV.

The decay time monitoring the fluorescence maxima in the free crown ethers (I to $\mathbf{V}$ ), the $\mathrm{Na}^{+}$ion complex of $\mathbf{I}$ and the $\mathrm{K}^{+}$ion complexes of II to $\mathbf{V}$ are presented in table 2 and figure 3 . For the free crown 
Table 1. Dihedral angles involving atoms in the centre of Naph- $\pi$ plane and the six oxygen atoms of naphtho-crown ethers (II to V).

\begin{tabular}{lcccccc}
\hline \multirow{7}{*}{ Dihedral angle $<\mathrm{C} 1-\mathrm{C} 9-\mathrm{C} 10-\mathrm{A}$} \\
System & $\mathrm{A}=\mathrm{O} 11^{\mathrm{a}}$ & $\mathrm{A}=\mathrm{O} 12^{\mathrm{a}}$ & $\mathrm{A}=\mathrm{O} 13^{\mathrm{a}}$ & $\mathrm{A}=\mathrm{O} 14^{\mathrm{a}}$ & $\mathrm{A}=\mathrm{O} 15^{\mathrm{a}}$ & $\mathrm{A}=\mathrm{O} 16^{\mathrm{a}}$ \\
\hline II & -23 & -27 & -38 & -20 & 0 & 20 \\
III & 165 & 138 & 167 & -160 & -152 & -151 \\
IV & 127 & 152 & 85 & 83 & 111 & $62 \cdot 0$ \\
V & 146 & 102 & 82 & 68 & 59 & 17 \\
\hline
\end{tabular}

${ }^{a}$ Atom numberings are as shown in figure 1

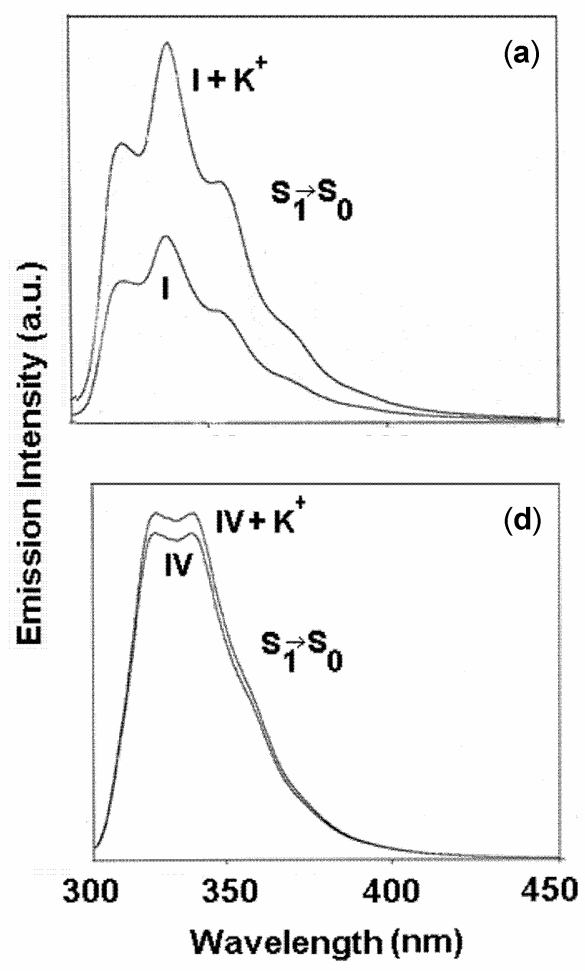

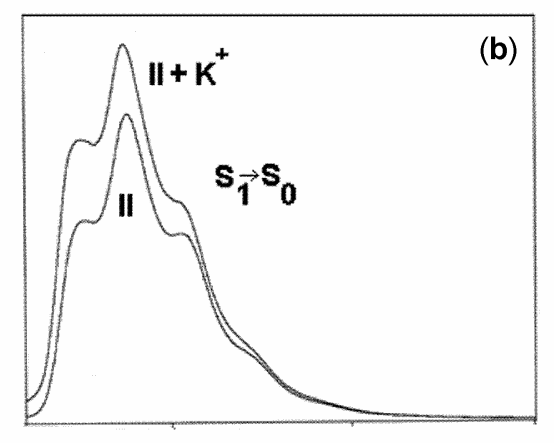

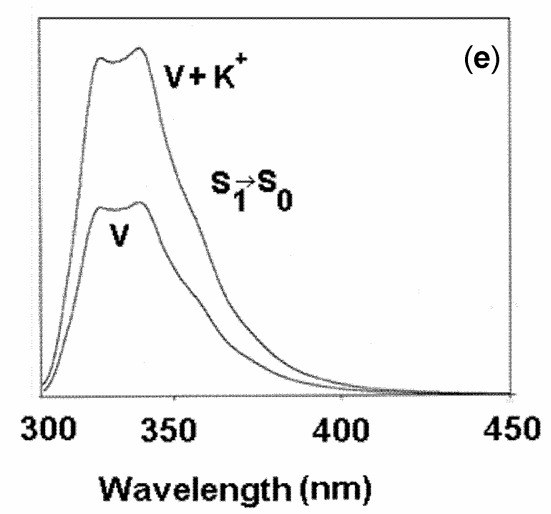

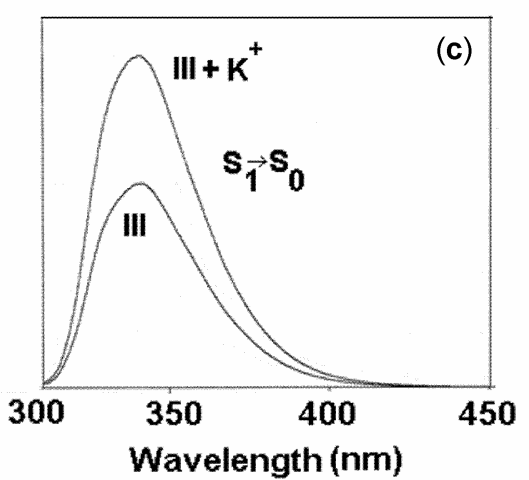

Figure 2. Emission spectra at $298 \mathrm{~K}$ in EtOH of (a) I and its $\mathrm{K}^{+}$complex; (b) II and its $\mathrm{K}^{+}$complex; (c) III and its $\mathrm{K}^{+}$complex; (d) IV and its $\mathrm{K}^{+}$complex; (e) $\mathbf{V}$ and its $\mathrm{K}^{+}$complex; concentrations of all the naphtho-crowns (I-V) were $10^{-4} \mathrm{M}$ and the concentration of added $\mathrm{K}^{+}$ion was $10^{-3} \mathrm{M} ; \lambda_{\mathrm{ex}}=290 \mathrm{~nm}$; Excitation and emission band pass $=5 \mathrm{~nm}$ each.

ethers (I, II, IV and V) the best fit is observed with two exponentials, while III shows a single exponential. A major difference in the two lifetime components is observed for I and II. The decay of metal ion complexes of $\mathbf{I}$ to $\mathbf{V}$ is best fit with one exponential in each case.

The order of the major lifetime component in the free crown ethers are as follows: $\tau_{1}{ }^{\mathrm{IV}}<\tau_{1}^{\mathrm{III}}<\tau_{1}{ }^{\mathrm{V}}<$ $\tau_{1}{ }^{\mathrm{I}}<\tau_{1}^{\mathrm{II}}$ (table 2). These are much shorter than the value of $80 \mathrm{~ns}^{20}$ measured for pure naphthalene in THF under identical experimental conditions. The lifetime of the each metal ion complex of all the crown ethers (I to $\mathbf{V}$ ) increases in each case (table 2) compared to that of the free crown ethers (figure 3 ).

The enhancement of quantum yield of fluorescence for the metal ion complexes of I and II and the single component of lifetime observed in the complexes (table 2) imply the following.

(i) The free crown ethers I and II have two conformers, i.e. one planar (the crown ring and the Naph are in the same plane) having greater quantum yield and lifetime, and the other non-planar (the crown ring is out of plane with respect to the Naph plane) having lower quantum yield and lifetime. This as- 
Table 2. Fluorescence quantum yields and singlet state lifetimes in the free and the metal-ion complexes of naphtha-crown-ethers in EtOH at $298 \mathrm{~K}$.

\begin{tabular}{lcccc}
\hline & & & & \multicolumn{2}{c}{$\begin{array}{c}\text { Singlet state lifetime monitoring } \\
\text { the emission maxima in each case }\end{array}$} \\
\cline { 3 - 4 } Systems* & $\begin{array}{c}\text { Position of the } \\
\text { emission maxima }(\mathrm{nm})\end{array}$ & $\begin{array}{c}\text { Fluorescence } \\
\text { quantum yield }\left(\varphi_{\mathrm{F}}\right)\end{array}$ & $\tau_{1}(\mathrm{~ns})$ & $\tau_{2}(\mathrm{~ns})$ \\
\hline $\mathbf{I}$ & $325 \cdot 8$ & $0 \cdot 112$ & $30 \cdot 3(77 \%)$ & $10 \cdot 2(23 \%)$ \\
I $+\mathrm{Na}^{+}$ & $325 \cdot 2$ & $0 \cdot 224$ & $29 \cdot 5(100 \%)$ & - \\
II & $325 \cdot 6$ & $0 \cdot 121$ & $36 \cdot 1(69 \%)$ & $12 \cdot 1(31 \%)$ \\
II $+\mathrm{K}^{+}$ & $326 \cdot 4$ & $0 \cdot 157$ & $30 \cdot 1(100 \%)$ & - \\
III & $341 \cdot 2$ & $0 \cdot 067$ & $13 \cdot 2(100 \%)$ & - \\
III $+\mathrm{K}^{+}$ & $340 \cdot 4$ & $0 \cdot 107$ & $14 \cdot 9(100 \%)$ & - \\
IV & $329 \cdot 2$ & $0 \cdot 054$ & $10 \cdot 4(81 \%)$ & $14 \cdot 9(19 \%)$ \\
IV $+\mathrm{K}^{+}$ & $329 \cdot 4$ & $0 \cdot 059$ & $13 \cdot 2(100 \%)$ & - \\
V & $328 \cdot 2$ & $0 \cdot 101$ & $19.7(53 \%)$ & $17 \cdot 5(47 \%)$ \\
V $+\mathrm{K}^{+}$ & $328 \cdot 6$ & $0 \cdot 182$ & $21.4(100 \%)$ & - \\
\hline
\end{tabular}

${ }^{*}$ Concentration of the crown ethers were $10^{-4} \mathrm{M}$ and the added metal ions were $10^{-3} \mathrm{M} ; \lambda_{\mathrm{ex}}=290 \mathrm{~nm}$
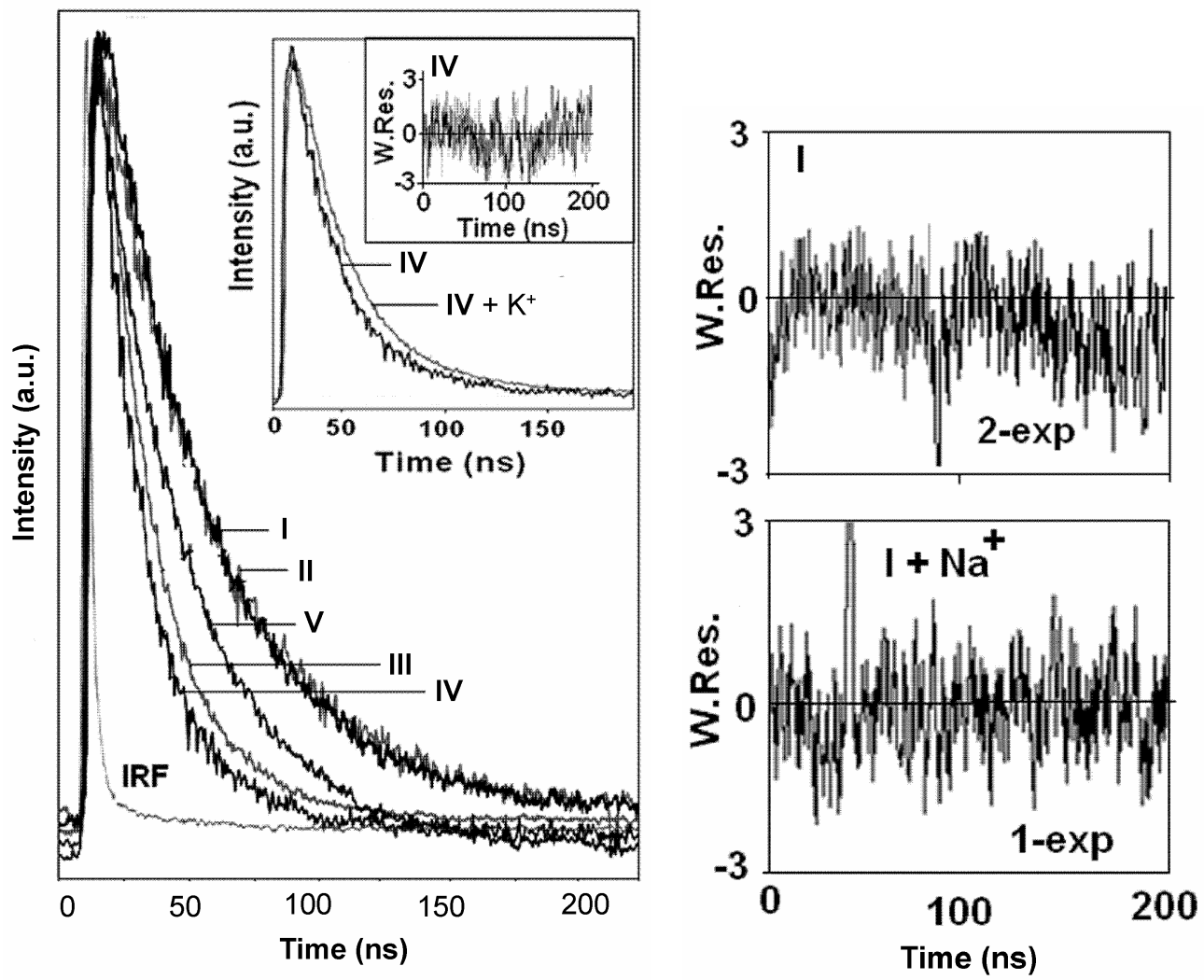

Figure 3. Decay of the naphtho-crowns $(\mathbf{I}-\mathbf{V})$ in EtOH $\left(10^{-4} \mathrm{M}\right)$ at $298 \mathrm{~K}$ monitoring the respective emission maxima with excitation at $297 \mathrm{~nm}$; Excitation and emission band pass $=10 \mathrm{~nm}$ each. Inset: Decay of free IV $\left(10^{-4} \mathrm{M}\right)$ and its $\mathrm{K}^{+}\left(10^{-3} \mathrm{M}\right)$ complex in EtOH at $298 \mathrm{~K}$ with excitation at $297 \mathrm{~nm}$; Excitation and emission band pass $=10 \mathrm{~nm}$ each.

signment is based on our heavy atom perturbation results $^{9,10}$ indicating that spin-orbit coupling is greater where the heavy atom perturber lies above the $\pi$ plane of the fluorophore. (ii) The complex formation of I with $\mathrm{Na}^{+}$and of II with $\mathrm{K}^{+}$result only planar conformer. This is supported by the planar structure of the complex of II with $\mathrm{K}^{+}$ion. ${ }^{19}$ 
Increase in fluorescence quantum yield for the metal ion complexes of the crown ethers could suggest photoinduced electron transfer (PET) from the oxygen atom of the crown ether moiety to Naph- $\pi$ plane in the free crown ethers. However, the different lifetimes for the crown ethers having different orientation of the crown ring with respect to Naph- $\pi$ plane and the value of major component of the lifetime $\left(\tau_{1}^{\mathrm{IV}}<\tau_{1}^{\mathrm{III}}<\tau_{1}^{\mathrm{V}}<\tau_{1}^{\mathrm{I}}<\tau_{1}^{\mathrm{II}}\right)$ (table 2$)$ observed for the free crown ethers ruled out the possibility of
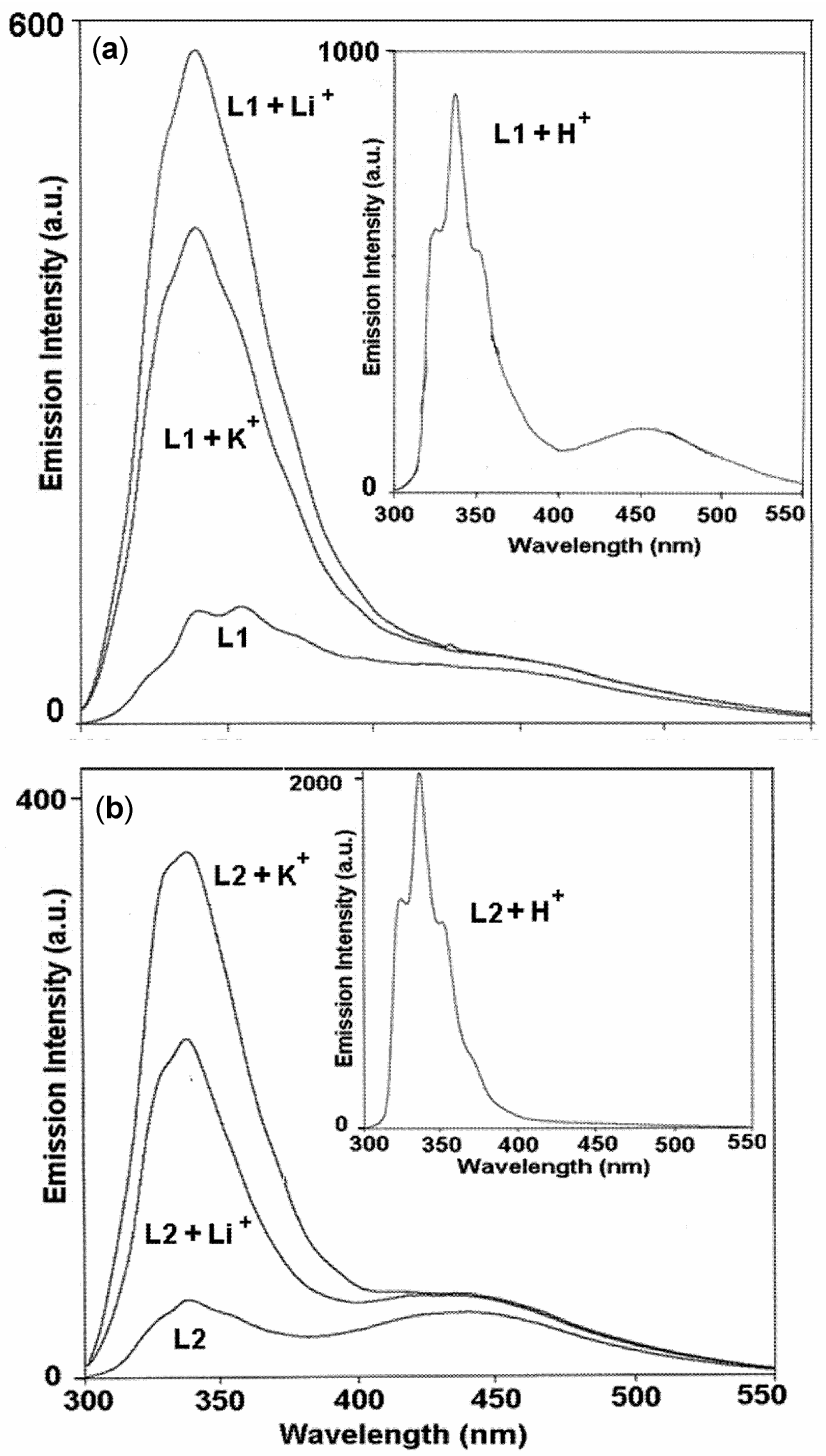

Figure 4. (a) Emission spectra in $\mathrm{THF}$ at $298 \mathrm{~K}$ of free $\mathrm{L} 1\left(10^{-4}\right)$ and its $\mathrm{Li}^{+}\left(10^{-3} \mathrm{M}\right)$ and $\mathrm{K}^{+}\left(10^{-3} \mathrm{M}\right)$ ion $\left(10^{-3} \mathrm{M}\right)$ complex; Inset: Emission spectrum of L1 in presence of $\mathrm{H}^{+}\left(10^{-3} \mathrm{M}\right)$. (b) Emission spectra in $\mathrm{THF}$ at $298 \mathrm{~K}$ of free L2 $\left(10^{-4} \mathrm{M}\right)$ and its $\mathrm{Li}^{+}\left(10^{-3} \mathrm{M}\right)$ and $\mathrm{K}^{+}\left(10^{-3} \mathrm{M}\right)$ complex; Inset: Emission spectrum of L2 in presence of $\mathrm{H}^{+}\left(10^{-3} \mathrm{M}\right) ; \lambda_{\mathrm{ex}}=290 \mathrm{~nm}$; excitation and emission band pass $=5 \mathrm{~nm}$ each.
PET process. The decreasing order of major component of lifetime $\left(\tau_{1}\right)$ in IV, III, $\mathbf{V}, \mathbf{I}$ and II suggest that the spin-orbit coupling due to the oxygen atoms is different in the crown ethers $\mathbf{I}$ to $\mathbf{V}$. The results then imply that the intersystem crossing (ISC) rate populating the lowest triplet state $\left(T_{1}\right)$ of Naph is maximum in IV and minimum in I and II. The interpretation is supported by our earlier studies on $\mathbf{I}$ to IV and their complexes with $\mathrm{Tl}^{+}$ion by low temperature triplet state and optical detection of magnetic resonance (ODMR) spectroscopy in zero magnetic field. ${ }^{9,10}$ These studies revealed that the heavy atom perturbation depends on the orientation of the heavy atom with respect to the Naph- $\pi$ plane and the perturbation is highest when the perturber is situated perpendicular to the Naph- $\pi$ plane. Thus, although the crystal structures of free crown ethers are not known, the results observed indicates that the crown ring in IV (1,5-naphtho-22-crown-6) containing six oxygen atoms is more or less perpendicular to the Naph- $\pi$ plane. This is supported by our calculations of the geometry of II to $\mathbf{V}$.

Furthermore, the difference in geometry of the metal ion complexes of $\mathbf{I}$ to $\mathbf{I V}$ with $\mathrm{Tb}^{3+}$ and $\mathrm{Eu}^{3+}$ ions resulting in difference in photoinduced energy transfer from the naphthalene-moiety to $\mathrm{Tb}^{3+} / \mathrm{Eu}^{3+}$ have been reported from our lab. ${ }^{11,12}$

The difference in vibrational features of the emission spectra in $\mathbf{I}$ to $\mathbf{V}$ could be attributed to substitution effect and the varying rigidity of the structures (crown ether ring is attached to 2,$3 ; 1,8 ; 1,5$; and 1,4 positions). This is supported by the similarity in vibrational features in I and II.

Table 3. Fluorescence quantum yields $(\phi)$ of L1 and L2 in presence of various ionic inputs in THF at $298 \mathrm{~K}$.

\begin{tabular}{lclcc}
\hline System $^{\mathrm{a}}$ & $\phi_{\text {MONOMER }}$ & \multicolumn{1}{c}{$\phi_{\mathrm{E}}{ }^{\mathrm{b}}$} & $\phi_{\text {TOTAL }}$ & $\phi_{\mathrm{Exp}} / \phi_{\mathrm{M}}$ \\
\hline Free L1 & 0.020 & $0.014^{\mathrm{c}}$ & 0.034 & 0.713 \\
$\mathrm{~L} 1+\mathrm{Li}^{+}$ & 0.089 & 0.03 & 0.119 & - \\
$\mathrm{L} 1+\mathrm{K}^{+}$ & 0.086 & 0.018 & 0.104 & - \\
$\mathrm{L} 1+\mathrm{H}^{+}$ & $0 \cdot 164$ & $0.07^{\mathrm{d}}$ & 0.234 & - \\
Free L2 & 0.004 & $0.007^{\mathrm{c}}$ & 0.011 & 1.72 \\
$\mathrm{~L} 2+\mathrm{Li}^{+}$ & 0.024 & 0.009 & 0.033 & - \\
$\mathrm{L} 2+\mathrm{K}^{+}$ & 0.033 & 0.008 & 0.041 & - \\
$\mathrm{L} 2+\mathrm{H}^{+}$ & 0.129 & - & - & - \\
\hline
\end{tabular}

${ }^{\mathrm{a}}$ Concentration of L1 and L2 in all cases is $10^{-4} \mathrm{M}$ and that of the added ionic inputs is $10^{-3} \mathrm{M}$; ${ }^{\mathrm{b}} \phi_{\mathrm{E}}$ indicates quantum yield of the broad band which includes both excimer and exciplex emissions; ' $q u a n t u m$ yield of only exciplex; ${ }^{\mathrm{d}}$ quantum yield of only excimer; $\phi_{\operatorname{Exp}}=$ quantum yield of exciplex 
3.3 Steady-state and time-resolved emission studies of photoinduced electron transfer (PET) in naphtho-aza crown ether $\mathrm{L} 1$ and $\mathrm{L} 2$ and their $\mathrm{Li}^{+}$ and $K^{+}$ion complexes

3.3a Emission study at room temperature (298 K): Free $L 1$ and $L 2$ - The fluorescence emission spectra of free L1 and L2 in dry THF consist of a structured naphthalene monomer emission from locally excited lowest ${ }^{1}\left(\pi-\pi^{*}\right)$ with the $(0,0)$ band at $\approx 328 \mathrm{~nm}$ and another broad band at $\approx 430-440 \mathrm{~nm}$ (figure 4 ). The position of the broad band shows a red shift with increasing solvent polarity and the intensity of this band diminishes at $77 \mathrm{~K} .{ }^{20}$ Moreover, the excitation spectra monitoring both the monomer and the broad emission bands of L1 and L2 in THF match well with their absorption spectra at $298 \mathrm{~K}$ excluding any possibility of ground-state complex formation. From these observations, it may be inferred that this broad band is due to an intramolecular exciplex emission. ${ }^{21,22}$ Similar intramolecular exciplex emission bands have also been reported earlier for other naphthalene cryptand systems. ${ }^{8,23}$

The ratio of quantum yields of exciplex to monomer $\left(\varphi_{\mathrm{Exp}} / \varphi_{\mathrm{M}}\right)$ is however, different in the two systems (table 3) which implies a different orientation of nitrogen lone pair of the aza crown moiety with respect to the Naph- $\pi$ plane in these two systems.

The total quantum yield for the emission of L1 and L2 (0.034 and 0.011 respectively) are lower compared to that of pure naphthalene in THF $(0 \cdot 23)$ (table 3) due to PET from the nitrogen atom of the aza crown ring to the Naph unit. Similar phenomena have been reported earlier in different kinds of naphthalene-amine donor-acceptor systems. $^{24-26}$ The higher quenching for L2 than for L1 suggests a more favourable 'in line approach' of the donor $\mathrm{N}$ atom and the acceptor naphthalene unit in L2 compared to that in L1.

\section{3b Effect of complex formation with $\mathrm{Li}^{+}$and $\mathrm{K}^{+}$} ions and protons: Complex formation with alkali metal ions such as $\mathrm{Li}^{+}, \mathrm{K}^{+}$in THF distinctly increases the emission of the monomer (figure 4, table 3). Upon complex formation, the metal ions in the cavity engage the lone pair on the $\mathrm{N}$ atom preventing PET and leading to enhanced fluorescence. The cavity dimensions of the ligand are always an important factor in metal ion discrimination in crown etheralkali metal ion complexes and the binding constants for the complex formation depend on the size of the metal ions. The selectivity trends for the various alkali metal ions is known to be $\mathrm{Li}^{+}>\mathrm{K}^{+}$for $15 \mathrm{C} 5$ crown ethers and that of the order $\mathrm{K}^{+}>\mathrm{Li}^{+}$for $18 \mathrm{C} 6$ crown ethers respectively. ${ }^{27,28}$ The fluorescence enhancement in the complexes of the two aza crown ethers L1 (15C5) and L2 (18C6) with the alkali metals indeed follow the same trend (table 3 ).

Addition of perchloric acids $\left(\mathrm{H}^{+}\right)$causes the nitrogen lone pair to be unavailable and the PET is thus switched off in the system. This results in considerable enhancement in the fluorescence emission of the aza-crowns (figure 4 and table 3 ). In presence of $\mathrm{H}^{+}$, the exciplex emission almost disappears in L2

Table 4. Singlet-state lifetimes of ligands L1 and L2 in various environments at $298 \mathrm{~K}$; $\lambda_{\mathrm{ex}}=297 \mathrm{~nm}$.

\begin{tabular}{lcc}
\hline System in THF & $\tau(\mathrm{ns})$ monitored at $337 \mathrm{~nm}$ & $\tau(\mathrm{ns})$ monitored at $430 \mathrm{~nm}$ \\
\hline L1 $\left(10^{-4} \mathrm{M}\right)$ & $33 \cdot 2(83 \%), 6 \cdot 1(17 \%)$ & $9.4(38 \%), 1 \cdot 8(62 \%)$ \\
L1 $\left(10^{-4} \mathrm{M}\right)+\mathrm{H}^{+}\left(10^{-3} \mathrm{M}\right)$ & $46 \cdot 0(83 \%), 7 \cdot 0(17 \%)$ & - \\
System in THF & $\tau(\mathrm{ns})$ monitored at $337 \mathrm{~nm}$ & $\tau(\mathrm{ns})$ monitored at $435 \mathrm{~nm}$ \\
L2 $\left(10^{-4} \mathrm{M}\right)$ & $24 \cdot 8(89 \%), 2 \cdot 9(11 \%)$ & $8 \cdot 9(54 \%), 1.6(46 \%)$ \\
L2 $\left(10^{-4} \mathrm{M}\right)+\mathrm{H}^{+}\left(10^{-3} \mathrm{M}\right)$ & $36 \cdot 3(98 \%), 2 \cdot 0(2 \cdot 42 \%)$ & - \\
\hline
\end{tabular}

Table 5. Radiative and non-radiative rates at $298 \mathrm{~K}$

\begin{tabular}{lcccc}
\hline Systems & Quantum yield $(\phi)$ & $\tau_{\text {av }}(\mathrm{ns})$ & $k_{f}\left(\mathrm{~s}^{-1}\right) \times 10^{-6}$ & $k_{n r}\left(\mathrm{~s}^{-1}\right) \times 10^{-7}$ \\
\hline Free L1 & 0.034 & 28.6 & 1.2 & 3.4 \\
Free L2 & $0 \cdot 011$ & 22.4 & $0 \cdot 5$ & 4.4 \\
2,3-Crown-6 (II) & $0 \cdot 121$ & 28.9 & $4 \cdot 2$ & 3.0 \\
1,5-Crown-6 (IV) & 0.054 & 18.7 & 2.9 & $5 \cdot 1$ \\
\hline
\end{tabular}


while in L1; a new broad band insensitive to solvent polarity appears at $455 \mathrm{~nm}$. On increasing the concentration of $\mathrm{Ll}$ at a fixed concentration of $\mathrm{H}^{+}$, the intensity of this band increases suggesting that this band is probably due to excimer emission. The excimer emission is present even in the presence of metal ions. One could speculate the formation of $2: 1$ (aza crown: metal ion) complexes ${ }^{29}$ which facilitate the formation of excimer.

3.3c Time resolved emission studies: MonomerIn order to characterize the different emissions observed in various environments, transient fluorescence measurement was carried out for $\mathrm{L} 1$ and $\mathrm{L} 2$ in various environments (table 4, figure 5). The major component of lifetime for L1 (33.2 ns) and L2 (24.8 ns) are shorter on account of PET as compared to that measured for free naphthalene $(80 \mathrm{~ns}$, ref. [20]) under identical conditions. The result is also reflected in the quantum yield values of the systems which indicate more efficient PET in L2 (table 3). The lifetimes are longer in the presence of $\mathrm{H}^{+}$where PET is switched off (table 4).

Exciplex - The exciplex emission from both $\mathrm{L} 1$ and L2 exhibit two components of $\approx 9 \mathrm{~ns}$ and $\approx 1.6$ to $1.7 \mathrm{~ns}$ (table 4 ) which possibly suggests two different exciplex geometries involving nitrogen lone pair of the aza crown ring and naphthalene $\pi$ plane

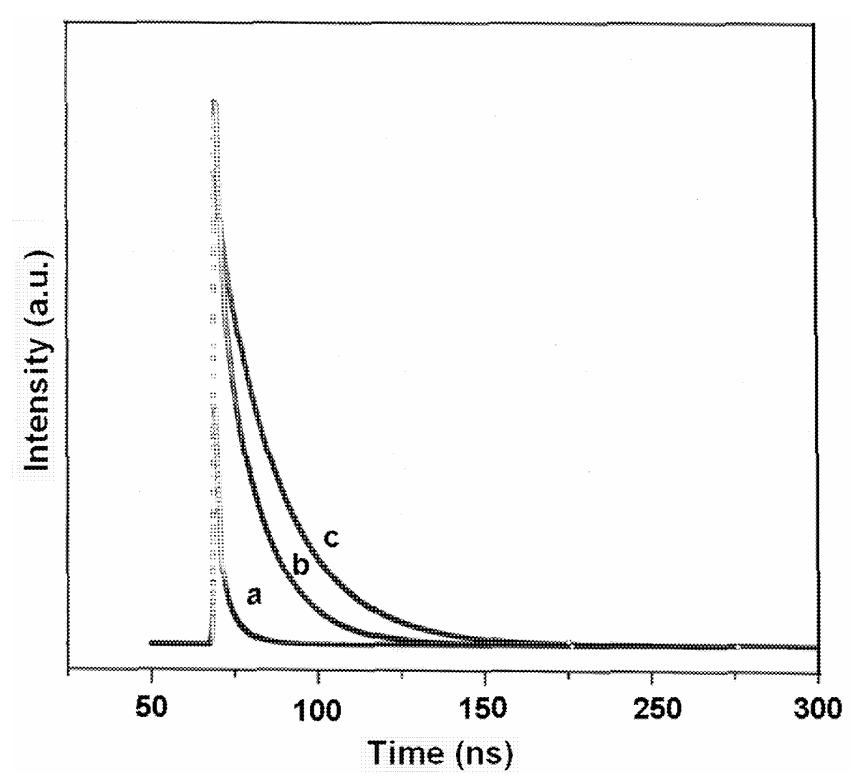

Figure 5. Fluorescence decay curves (fitted) for L2 $\left(10^{-4} \mathrm{M}\right)$ monitored at (a) $435 \mathrm{~nm}$, (b) $337 \mathrm{~nm}$ and (c) L2 $\left(10^{-4} \mathrm{M}\right)$ in presence of $\mathrm{H}^{+}\left(10^{-3} \mathrm{M}\right)$ monitored at $337 \mathrm{~nm}$. $\lambda_{\mathrm{ex}}=297 \mathrm{~nm}$; Excitation and emission band pass $=10 \mathrm{~nm}$ each. for the ligands. The value of lifetime of $\approx 1.7 \mathrm{~ns}$ obtained in our systems is close to the value of $\approx 2 \mathrm{~ns}$ reported earlier for semi-rigid systems involving tertiary amine groups and polycyclic aromatic hydrocarbon moiety. ${ }^{30,31}$ However, they are lower than that reported for (10 ns) unlinked aromatic hydrocarbontertiary amine systems. ${ }^{32}$ The shortening of lifetime in the aza-crown systems may be due to (i) the inherent strain within this intramolecular CT state and (ii) the increased rate of back electron transfer due to close proximity of the $\mathrm{D}-\mathrm{A}$ pair compared with that in intermolecular exciplexes of tertiary amines. The details of the time-resolved studies of the exciplex and excimer emissions of L1 and other aza crown ethers under various conditions are in progress and will be reported elsewhere.

A comparative account of the $\varphi, \tau, k_{f}$ and $k_{n r}$ for the aza crown ethers L1 and L2 and the crown ethers II and IV are presented in table 5. The differences are due mainly to the differences in photoinduced electron transfer (PET) in L1 and L2 due to different orientations of nitrogen lone pairs with respect to the Naph- $\pi$ plane. Although the spacer $\left(-\mathrm{CH}_{2}-\right)$ between the fluorophore Naph and nitrogen atom in the aza crown ethers L1 and L2 is same, the different flexibility of the rings leads to different orientations of the lone pair of nitrogen atom and the $\pi$-plane of Naph.

The difference in the photophysical behaviour of II and IV is due to the different spin-orbit coupling since the crown ring is mainly planar in I with respect to the naph- $\pi$ plane whereas the crown ring is perpendicular to the naph- $\pi$ plane in IV. In our earlier work in naphthalene crown ether metal ion (alkali, $\mathrm{Tl}^{+}$and $\mathrm{Ag}^{+}$) complexes, it was observed that the largest heavy atom effect results when the metal-ion perturber is located along the out-of-plane axis originating from the centre of the naphthalene chromophore. This was attributed to the symmetry restrictions which enter the spin-orbit matrix elements via the overlap integrals between the $\pi$-electrons of naphthalene and the $p$ orbitals of the heavy atom. ${ }^{9,10}$

\section{Conclusion}

The effect of orientation of six-membered and fivemembered crown ethers with respect to Naph- $\pi$ plane in naphthalene-linked crown ethers on the photophysical properties have been explored in detail. The spin-orbit coupling factor depending on the geome- 
try plays a major role in determining quantum yields and lifetimes for $\mathbf{I}$ to $\mathbf{V}$.

The systems L1 and L2 exhibit PET at room temperature resulting in reduced fluorescence quantum yields as well as quenched singlet-state lifetimes compared to that of free naphthalene. Both the systems show exciplex emission, though the ratio of yields of exciplex to monomer emission is different in the two systems on account of different geometries of the two systems. In complexes with alkali metal ions, there is significant enhancement of naphthalene fluorescence, the extent of fluorescence enhancement following the same trend as the binding constants of the metal ions in the two ligands. Protonation leads to excimer formation in Ll only.

\section{Acknowledgements}

SG and SM gratefully acknowledge Department of Science and Technology for financial support. SS, PSS and AP thank the Council of Scientific and Industrial Research, Department of Science and Technology and University Grants Commission respectively for fellowships.

\section{References}

1. (a) Bissell A R, De Silva A P, Gunaratne H Q N, Maguire G E M, McCoy C P and Sandanayake K R A S 1993 Top. Curr. Chem. 168 223; (b) De Silva A P, Gunaratne H Q N, Gunnlaugsson T, Huxley A J M, McCoy C P, Rademacher J T and Rice T E 1997 Chem. Rev. 97 1515; (c) Bissell A R, De Silva A P, Gunaratne H Q N, Lynch P L M, Maguire G E M and Sandanayake K R A S 1992 Chem. Soc. Rev. 21187

2. (a) Czarnik A W 1994 Acc. Chem. Res. 27 302; (b) Czarnik A W (ed.) 1993 Fluorescent chemosensors for ion and molecular recognition (Washington, DC: Am. Chem. Soc.); (c) Czarnik A W 1995 Chem. Biol. 2423

3. (a) Lakowicz J R (ed.) 1994 Topics in fluorescence spectroscopy (New York: Plenum) vol. 4; (b) Lehn J M 1995 Supramolecular chemistry-Concepts and perspectives (Weinheim: VCH)

4. Iwata S and Tanaka K J $1995 \mathrm{~J}$. Chem. Soc., Chem. Commun. 1491

5. Ghosh P, Bharadwaj P K, Mondal S and Ghosh S 1996 J. Am. Chem. Soc. 1181553

6. Ghosh P, Bharadwaj P K, Roy J and Ghosh S 1997 J. Am. Chem. Soc. 11911903

7. Bandyopadhyay $\mathrm{P}$, Bharadwaj $\mathrm{P} \mathrm{K}$, Basu Roy M, Dutta R and Ghosh S 2000 Chem. Phys. 255325
8. Das G, Bharadwaj P K, Basu Roy M and Ghosh S 2002 Chem. Phys. 277145

9. Ghosh S, Petrin M, Maki A H and Sousa L R 1987 J. Chem. Phys. 874315

10. Ghosh S, Petrin M, Maki A H and Sousa L R 1988 J. Chem. Phys. 882913

11. Bhattacharyya S, Sousa L R and Ghosh S 1998 Chem. Phys. Lett. 297154

12. Bhattacharyya S, Basu Roy M and Ghosh S 2004 Chem. Phys. 300295

13. Pederson C J and Frensdorff H K 1972 Angew. Chem. 1116

14. Ghosh S, Misra A, Ozarowski A, Stuart C and Maki A H 2001 Biochemistry 4015024

15. Ghosh S, Misra A, Ozarowski A and Maki A H 2003 J. Phys Chem. B107 11520

16. Sousa L R and Larson J M $1977 \mathrm{~J}$. Am. Chem. Soc. 99307

17. Isak S J and Eyring E M 1992 J. Phys. Chem. 96 1738

18. (a) Frisch M J et al 2003 Gaussian 03, Revision A.1, Gaussian, Inc., Pittsburgh, PA; (b) Foresman J B and Frisch A (eds) 1996 Exploring chemistry with electronic structure methods (Pittsburgh, PA: Gaussian)

19. Ward D L, Brown H S and Sousa L R 1977 Acta Crystallogr. B33 3537

20. Basu Roy M, Samanta S, Chattopadhyay G and Ghosh S 2004 J. Lumin. 106141

21. Horvath A and Stevenson K L 1996 Coord. Chem. Rev. 15357

22. Das A, Mahato K K and Chakraborty T 2001 J. Chem. Phys. 1146107

23. Hermant R M, Bakker N A C, Scherer T, Krijnen B and Verhoeven J W $1990 \mathrm{~J}$. Am. Chem. Soc. 1121214

24. Meeus F, van der Auweraer M and De Schrijver F C 1980 Chem. Phys. Lett. 74218

25. Davidson R S and Trethewey K R 1976 J. Chem. Soc., Chem. Commun. 827

26. Ballardini R, Balzani V, Credi A, Gandolfi M T, Kotzyba-Hibert F and Lehn J M $1994 \mathrm{~J}$. Am. Chem. Soc. 1165741

27. (a) Bradshaw J S, Izatt R M, Bordunov A V, Zhu C Y and Hathaway J K 1996 In Comprehensive supramolecular chemistry (ed.) G W Gokel (New York: Pergamon) vol. 1, p. 36; (b) Atwood J L, Davies J E D, MacNicol D D and Vogtle F (eds) 1996 Molecular recognition: Receptors for cationic guests (New York: Pergamon)

28. Mazor M H, McCammon J A and Lybrand T P 1990 J. Am. Chem. Soc. 1124411

29. Simon J D, Moomaw R W and Ceckler T M $1985 \mathrm{~J}$. Phys. Chem. 895659

30. Brun M, Harriman A, Tsuboi Y, Okada T and Mataga N 1995 J. Chem. Soc. Faraday Trans. 914047

31. Bera P K, Chakraborty A and Chowdhury M 1997 Chem. Phys. Lett. 27757

32. Bhattacharyya K and Chowdhury M 1993 Chem. Rev. 91507 